\title{
Spectral harmonic analysis and synthesis of Earth's crust gravity field
}

\author{
Robert Tenzer • Pavel Novák • Peter Vajda • \\ Vladislav Gladkikh • Hamayun
}

Received: 2 May 2011 / Accepted: 17 October 2011 / Published online: 12 November 2011

(C) Springer Science+Business Media B.V. 2011

\begin{abstract}
We developed and applied a novel numerical scheme for a gravimetric forward modelling of the Earth's crustal density structures based entirely on methods for a spherical analysis and synthesis of the gravitational field. This numerical scheme utilises expressions for the gravitational potentials and their radial derivatives generated by the homogeneous or laterally varying mass density layers with a variable height/depth and thickness given in terms of spherical harmonics. We used these expressions to compute globally the complete crustcorrected Earth's gravity field and its contribution generated by the Earth's crust. The gravimetric forward modelling of large known mass density structures within the Earth's crust is realised by using global models of the Earth's gravity field (EGM2008), topography/bathymetry (DTM2006.0), continental icethickness (ICE-5G), and crustal density structures (CRUST2.0). The crust-corrected gravity field is
\end{abstract}

R. Tenzer $(\bowtie) \cdot$ V. Gladkikh

National School of Surveying, University of Otago,

Box 56, 310 Castle Street, Dunedin, 9054, New Zealand

e-mail: robert.tenzer@otago.ac.nz

P. Novák

Department of Mathematics, University of West Bohemia,

Univerzitní 22, Plzeň, Czech Republic

P. Vajda

Geophysical Institute, Slovak Academy of Sciences,

Dúbravská cesta 9, Bratislava, Slovak Republic

Hamayun

Delft Institute of Earth Observation and Space Systems (DEOS), Delft University of Technology, Kluyverweg 1, Delft, The Netherlands obtained after modelling and subtracting the gravitational contribution of the Earth's crust from the EGM2008 gravity data. These refined gravity data mainly comprise information on the Moho interface and mantle lithosphere. Numerical results also reveal that the gravitational contribution of the Earth's crust varies globally from 1,843 to $12,010 \mathrm{mGal}$. This gravitational signal is strongly correlated with the crustal thickness with its maxima in mountainous regions (Himalayas, Tibetan Plateau and Andes) with the presence of large isostatic compensation. The corresponding minima over the open oceans are due to the thin and heavier oceanic crust.

Keywords Crust • Forward modelling • Gravity field • Spectral representation $\cdot$ Synthetic model of the Earth

\section{Introduction}

Various methods have been developed and applied to compute topographic gravity corrections. Studying the global long-wavelength Earth's gravity field, the spectral representation of Newton's integral is typically utilised in deriving expressions for the forward modelling of the topography-generated gravitational field. Sünkel [50] derived spectral expressions for computing the topographic and topographic-isostatic potentials by means of spherical height functions. Grafarend and Engels [14] and Grafarend et al. [15] formulated expressions for an evaluation of the gravitational potential generated by topographic-isostatic masses. Alternative expressions for the topographic potential and its radial derivative were formulated in Vaníček et al. [70]. Sjöberg and Nahavandchi [42], 
Tsoulis [63], Sjöberg [43], Novák [29], Novák et al. [30], Tsoulis [64], Sjöberg [45], Heck [16], Tenzer [51], Sjöberg [47] and Novák [33] derived various expressions for computing parameters of the topographygenerated gravitational field by using methods for a spherical harmonic analysis and synthesis. Wild and Heck [71] introduced expressions for topographic effects on satellite gradiometry. Makhloof [25] derived expressions for computing topographic-isostatic effects on airborne and spaceborne gravimetry, and gradiometry data. Alternative expressions for computing topographic effects in spaceborne gravimetry and gradiometry applications were formulated by Novák and Grafarend [32] and Eshagh and Sjöberg [7, 8]. Novák and Grafarend [31] derived the topographic potential and its radial derivative using the ellipsoidal representation of Newton's integral.

Sjöberg [39, 40] and Sjöberg and Nahavandchi [42] defined atmospheric effects on the gravity and the geoid using the spherical harmonic analysis. This concept was further developed in Sjöberg [41, 45] and Sjöberg and Nahavandchi [44]. In these studies, geometry of the lower atmospheric bound is described by spectral coefficients of a global elevation model. Ramillien [37] applied a similar concept to compute the atmosphere-generated gravitational attraction. Nahavandchi [28] computed the direct atmospheric gravity effect on a regular grid at the Earth's surface over the territory of Iran including offshore areas. He combined the local and global topographic information using detailed digital terrain models and global elevation model coefficients. Sjöberg [46] derived expressions in the spectral representation for the atmospheric potential and its radial derivative considering the ellipsoidal layering of the Earth's atmosphere. Atmospheric effects in satellite geodesy applications were discussed by Novák and Grafarend [32] and Eshagh and Sjöberg [8]. Novák and Grafarend [32] proposed a method for computing the gravitational effect of atmospheric masses on spaceborne data based on the spherical harmonic approach with a numerical study in North America. Eshagh and Sjöberg [8] applied an alternative spherical approach to compute the atmospheric effect on satellite gravity gradiometry data over Fennoscandia. Tenzer el al. [55] applied the analytical continuation approach in deriving expressions for modelling the atmospheric gravity corrections in a form of the spherical height functions.

Tenzer et al. [52-54, 57] computed globally bathymetric stripping corrections to gravity field parameters using a spherical harmonic approach. In all these studies, a constant value of the seawater density was adopted. Novák [32] computed globally the gravita- tional potential generated by the ocean saltwater density with a high-degree spectral resolution. Tenzer et al. $[59,60]$ facilitated a depth-dependent seawater density model in deriving expressions for computing the bathymetric stripping gravity corrections in order to reduce large errors otherwise presented in results when using only a constant seawater density. These expressions utilise the spherical bathymetric functions for the spectral definition of the bathymetry-generated gravity field. The expressions for computing the ice density contrast stripping corrections to gravity data given in terms of spherical harmonics were derived in Tenzer et al. [58]. The convergence and optimal truncation of the binomial series associated with spherical harmonic representation of the gravity field were studied in detail, for instance, by Rummel et al. [38], Sun and Sjöberg [49], and Novák [34].

In geophysical studies investigating the lithosphere structure, the gravitational effect of the known subsurface mass density distribution is modelled and subsequently removed from observed gravity in order to reveal the remaining gravitational signal of the unknown (and sought) anomalous subsurface density distribution or the density interface (cf., e.g., [20-23]). Studies of the global crustal model CRUST2.0 can be found in Tsoulis [65, 66], Tsoulis and Venesis [67] and Tsoulis et al. [68]. The gravimetric methods for recovery of the Moho density interface were developed and applied, for instance, by Arabelos et al. [1], Sjöberg [48], and Eshagh et al. [9]. Tenzer et al. [52-54] combined various methods for the gravimetric forward modelling of known anomalous density structures within the Earth's crust based on the spectral harmonic representation (of topographic and bathymetric stripping gravity corrections) and using the analytical integration approach, which utilise the spatial representation of Newton's integral (for computing the ice, sediments, and crust components stripping gravity corrections).

In this study, we describe all the Earth's crust density structures uniformly by means of spherical functions which define the lower and upper bounds of homogeneous or laterally varying crustal components mass density layers with a variable height/depth and thickness. The corresponding gravitational field quantities describing the Earth's inner structure down to the Moho density interface are then defined based entirely on methods for a spherical harmonic analysis and synthesis of gravity field (Section 2). The currently available data of the mass density structure within the Earth's crust are then used to compute globally the gravity field parameters generated by the Earth's crust. These results are presented and discussed in 
numerical examples (Section 3). Expectations for a further improvement of synthetic models which describe the Earth's gravity field are finally indicated (Section 4). We note that a discussion on isostatic models is out of the scope of this study.

\section{Spherical harmonic representation of the crust-corrected gravity field}

A determination of the refined gravity field generated by the regularised Earth without its crust can numerically be realised by the gravitational forward modelling of the inhomogeneous crust density structures. Alternatively, it can be done in a two-step numerical scheme consisting of the gravimetric forward modelling of inhomogeneous crust density contrast structures and of the consequent gravimetric forward modelling of a homogeneous crust. The refined gravity field obtained after applying the gravimetric crust density contrast stripping corrections to observed gravity represents the consolidated crust-stripped gravity field generated by the regularised Earth with the homogeneous crust of adopted reference (constant) density (cf. [54]). The refined gravity field of the regularised Earth without its crust (i.e., the crust-corrected Earth's gravity field) is then obtained after subtracting the gravitational field generated by a homogeneous crust. In our numerical studies, the gravimetric forward modelling of the homogeneous crust is done individually for topography (i.e., application of the topographic correction) and for remaining homogeneous crust beneath the geoid, both having a constant reference crust density. This numerical scheme is followed in deriving spectral expressions for computing the crust-corrected gravity field.

In the following, parameters describing the disturbing and anomalous Earth's gravity field are used. Among them the most important one is the disturbing gravity potential $T$ defined as a difference of the actual and reference (or normal) gravity potentials (e.g. Heiskanen and Moritz, [17], Sections 2-13). Outside the Earth's masses (satisfying Laplace's differential equation), this potential is represented at the position $(r, \Omega)$ through the spherical harmonic series (e.g. [17], pp. 85-86)

$$
\begin{aligned}
& T(r, \Omega) \\
& \quad=\frac{G M}{R} \sum_{n=0}^{\bar{n}}\left(\frac{R}{r}\right)^{n+1} \sum_{m=-n}^{n} T_{n, m} Y_{n, m}(\Omega), \quad \forall r \geq R,
\end{aligned}
$$

$\mathrm{GM}=3,986,005 \times 10^{8} \mathrm{~m}^{3} / \mathrm{s}^{2}$ is the geocentric gravitational constant and the mean Earth's radius $\mathrm{R}=6,371 \times$ $10^{3} \mathrm{~m}$ approximates geocentric radii of the geoid. $Y_{n, m}$ are the surface spherical harmonic functions of degree $n$ and order $m, T_{n, m}$ are respective spherical harmonic coefficients and $\bar{n}$ is their maximum available degree (the series is generally infinite). The 3-D position is defined in geocentric spherical coordinates $(r, \Omega)$; where $r$ is the geocentric radius and the pair $\Omega=(\phi, \lambda)$ denotes the geocentric direction with spherical latitude $\phi$ and longitude $\lambda$. The coefficients $T_{n, m}$ are derived from the coefficients of global geopotential model (GGM) by subtracting the spherical harmonic coefficients of the normal gravity field ([17], p. 88). Finally, the general condition of $r \geq R$ applies throughout the article without being explicitly repeated in each relevant equation. The gravity disturbance $\delta g$ reads in the spherical approximation as ([62], p. 271)

$$
\begin{aligned}
\delta g(r, \Omega) & =-\frac{\partial T(r, \Omega)}{\partial r} \\
& =\frac{\mathrm{GM}}{R^{2}} \sum_{n=0}^{\bar{n}}\left(\frac{R}{r}\right)^{n+2}(n+1) \sum_{m=-n}^{n} T_{n, m} Y_{n, m}(\Omega) .
\end{aligned}
$$

The gravity anomaly $\Delta g$ is defined through the fundamental gravimetric formula ([62], p. 271)

$$
\begin{aligned}
\Delta g(r, \Omega) & =\delta g(r, \Omega)-\frac{2}{r} T(r, \Omega) \\
& =\frac{\mathrm{GM}}{R^{2}} \sum_{n=0}^{\bar{n}}\left(\frac{R}{r}\right)^{n+2}(n-1) \sum_{m=-n}^{n} T_{n, m} Y_{n, m}(\Omega) .
\end{aligned}
$$

The term $2 r^{-1} T$ in Eq. 3 is the so-called secondary indirect effect. The parameters $T, \Delta g$ and $\delta g$ will be reduced for gravitational effects of selected known Earth's mass components.

The consolidated crust-stripped disturbing gravity potential $T^{c}$ is computed from the disturbing gravity potential $T$ by using the following expression

$$
\begin{aligned}
T^{c}(r, \Omega)= & T(r, \Omega)-V^{t}(r, \Omega)+V^{b}(r, \Omega) \\
& +V^{i}(r, \Omega)+V^{s}(r, \Omega)+V^{c}(r, \Omega),
\end{aligned}
$$

where $V^{t}, V^{b}, V^{i}, V^{s}$ and $V^{c}$ are, respectively, gravitational potentials generated by topography and density contrasts due to ocean water, ice, sediments and remaining anomalous density structures within the Earth's crust. These potentials are discussed in this section as well as their vertical gradients (corresponding gravitational attractions) denoted hereto as $g^{t}, g^{b}$, 
Table 1 Statistics of the topographic and crust-stripping corrections to gravity disturbances

\begin{tabular}{lcccc}
\hline $\begin{array}{l}\text { Corrections to } \\
\text { gravity disturbances }\end{array}$ & Min [mGal] & Max [mGal] & Mean [mGal] & STD [mGal] \\
\hline Topographic & -659 & -19 & -70 & 98 \\
Bathymetric & 127 & 650 & 330 & 159 \\
Ice & 3 & 314 & 21 & 56 \\
Sediment & 14 & 125 & 35 & 20 \\
Upper crust & -122 & 9 & -38 & 35 \\
Middle crust & -250 & -68 & -117 & 44 \\
Lower crust & -529 & -118 & -185 & 66 \\
\hline
\end{tabular}

$g^{i}, g^{s}$ and $g^{c}$, respectively. By analogy with Eq. 4, the consolidated crust-stripped gravity disturbance $\delta g^{c}$ is defined as

$$
\begin{aligned}
\delta g^{c}(r, \Omega)= & \delta g(r, \Omega)-g^{t}(r, \Omega)+g^{b}(r, \Omega) \\
& +g^{i}(r, \Omega)+g^{s}(r, \Omega)+g^{c}(r, \Omega) .
\end{aligned}
$$

In Eqs. 4 and 5, the consolidated crust-stripped gravity field parameters $T^{c}$ and $\delta g^{c}$ are obtained from the corresponding disturbing gravity field parameters $T$ and $\delta g$ after subtracting the gravitational contribution of topographic masses and after a subsequent application of stripping corrections due to anomalous density structures within the Earth's crust. The computation of the consolidated crust-stripped gravity anomaly $\Delta g^{c}$ from the consolidated crust-stripped gravity disturbance $\delta g^{c}$ is done by applying the secondary indirect topographic and crust density contrast effects, see Eq. 3,

$$
\begin{aligned}
& \Delta g^{c}(r, \Omega)=\delta g^{c}(r, \Omega) \\
&-\frac{2}{r}[ T(r, \Omega)-V^{t}(r, \Omega)+V^{b}(r, \Omega) \\
&\left.\quad+V^{i}(r, \Omega)+V^{s}(r, \Omega)+V^{c}(r, \Omega)\right] .
\end{aligned}
$$

[There is also the atmospheric effect to be considered. However, Tenzer et al. [55] demonstrated that the atmospheric correction to gravity disturbances varies between -0.18 and $0.03 \mathrm{mGal}$, and the complete atmospheric correction to gravity anomalies varies from 1.13 to $1.76 \mathrm{mGal}$. These values are very small compared to the topographic and crust-stripping gravity corrections (see Tables 1 and 2 in Section 3), thus, the atmospheric effects are not considered in the context of this study.]

In this paragraph, reduction and stripping corrections applied in Eqs. 4-6 are defined in a general way. The approach originates in spatial (integral) formulation of the Newtonian potential that is generated by masses bounded by two closed 2-D surfaces, e.g., the internal or lower surface $r_{l}(\Omega)$ and the external or upper surface $r_{u}(\Omega)$. The mass density distribution within the layer is then either constant or laterally varying. For laterally varying density $\rho$, the general potential can be written as

$V(r, \Omega)=\mathrm{G} \iint_{\Phi} \rho\left(\Omega^{\prime}\right) \int_{r_{l}\left(\Omega^{\prime}\right)}^{r_{u}\left(\Omega^{\prime}\right)} L^{-1}\left(r, \Omega, r^{\prime}, \Omega^{\prime}\right) \mathrm{d} r^{\prime} \mathrm{d} \Omega^{\prime}$.

$\Phi$ is the full solid angle, and $L$ is the Euclidean distance. The two bounding surfaces can be represented by the following series expansion $\left(r_{l}\right.$ is defined relatively to the reference sphere of radius $\mathrm{R}$ through $H^{l}$ and $r_{u}$ through $H^{u}$ )

$r(\Omega)=R+H(\Omega)=R+\sum_{n=0}^{\bar{n}} \sum_{m=-n}^{n} H_{n, m} Y_{n, m}(\Omega)$,

where the height function $H$ defines the bounding surfaces external to the reference sphere. In case of the
Table 2 Statistics of the topographic and crust-stripping corrections to gravity anomalies

\begin{tabular}{lcrcc}
\hline $\begin{array}{l}\text { Corrections to } \\
\text { gravity anomalies }\end{array}$ & Min [mGal] & Max [mGal] & Mean [mGal] & STD [mGal] \\
\hline Topographic & -414 & 138 & 42 & 72 \\
Bathymetric & -595 & -132 & -374 & 99 \\
Ice & -53 & 210 & -1 & 36 \\
Sediment & -65 & 41 & -34 & 15 \\
Upper crust & -37 & 80 & 30 & 24 \\
Middle crust & 10 & 165 & 110 & 28 \\
Lower crust & -50 & 262 & 182 & 41 \\
\hline
\end{tabular}


internal surface, the depth function $D$ will be used. Developing the inverse distance function $L^{-1}$ into a series of spherical harmonics ([17], Sections 1-15) and solving the innermost integral in Eq. 7 yield the potential in the form

$V(r, \Omega)=4 \pi G R^{2} \sum_{n=0}^{\bar{n}}\left(\frac{R}{r}\right)^{n+1} \frac{1}{2 n+1} \sum_{m=-n}^{n} V_{n, m} Y_{n, m}(\Omega)$.

Coefficients $V_{n, m}$ are defined as follows [31]

$V_{n, m}=\sum_{k=0}^{\infty}\left(\begin{array}{c}n+2 \\ k\end{array}\right) \frac{(-1)^{k}}{k+1} \frac{F_{n, m}^{u(k+1)}-F_{n, m}^{l(k+1)}}{R^{k+1}}$.

Coefficients $F_{n, m}^{u}$ and their powers can be computed by the spherical analysis $\left(F_{n, m}^{l}\right.$ are defined respectively for $H^{l}$ )

$\mathrm{F}_{\mathrm{n}, \mathrm{m}}^{u(k+1)}=\iint_{\Phi} \rho\left(\Omega^{\prime}\right)\left[H^{u}\left(\Omega^{\prime}\right)\right]^{k+1} \mathrm{Y}_{\mathrm{n}, \mathrm{m}}{ }^{*}\left(\Omega^{\prime}\right) \mathrm{d} \Omega^{\prime}$,

with the complex conjugates of spherical harmonic functions $Y_{n, m}{ }^{*}$. Using the geocentric gravitational constant of the homogeneous spherical Earth with density $\rho^{\text {earth }}=5,500 \mathrm{~kg} / \mathrm{m}^{3}$, i.e.,

$\mathrm{GM}=\frac{4 \pi}{3} \rho^{\mathrm{earth}} G R^{3}$,

the potential in Eq. 9 is rewritten in a manner consistent with Eq. 1

$V(r, \Omega)=\frac{\mathrm{GM}}{R} \sum_{n=0}^{\bar{n}}\left(\frac{R}{r}\right)^{n+1} \sum_{m=-n}^{n} V_{n, m} Y_{n, m}(\Omega)$,

with coefficients $V_{n, m}$ defined as

$$
\begin{aligned}
V_{n, m}= & \frac{3}{2 n+1} \\
& \times \frac{1}{\rho^{\text {earth }}} \sum_{k=0}^{\infty}\left(\begin{array}{c}
n+2 \\
k
\end{array}\right) \frac{(-1)^{k}}{k+1} \frac{F_{n, m}^{u}{ }^{(k+1)}-F_{n, m}^{l}{ }^{(k+1)}}{R^{k+1}} .
\end{aligned}
$$

The method is described in all details in [31]. The density function can also vary radially (only bathymetry in this study) which results in more complicated expressions than given in Eq. 14. On the other hand, if a constant density is considered (e.g. topography) then Eq. 11 concerns only height or depth functions. Corrections to gravity disturbances can be then derived by applying Eq. 2, corrections to gravity anomalies by applying Eq. 3.
The reduction and stripping corrections due to particular masses can be computed if geometry of their bounding surfaces is known as well as their mass density distribution. Starting with topography, we consider solid masses outside the geoid. In spherical approximation, the lower bounding surface is the geocentric reference sphere, the upper bounding surface is the surface of the Earth represented relatively to the reference sphere by topographical height function $H^{t u}$ (positive over continents, zero over oceans). The average density of the upper continental crust $2,670 \mathrm{~kg} / \mathrm{m}^{3}$ (cf. [18]) is adopted as the mean topographical mass is adopted as the mean topographical mass density $\rho^{t}$. Coefficients of the read, see [33],

$V_{n, m}{ }^{t}=\frac{3}{2 n+1} \frac{\rho^{t}}{\rho^{\text {earth }}} \sum_{k=0}^{\infty}\left(\begin{array}{c}n+2 \\ k\end{array}\right) \frac{(-1)^{k}}{k+1} \frac{F_{n, m}^{t u(k+1)}}{R^{k+1}}$,

Coefficients $F_{n, m}^{t u}$ are derived by the spherical analysis of the height function $H^{t u}$ (and its powers) obtained from the global elevation model (GEM), see Eq. 11. Topography represents the external boundary; coefficients $F_{n, m}^{t l}$ for the internal boundary are equal to zero since the spherical approximation of the geoid is used.

Tenzer et al. [59, 60] derived spectral expressions for computing the bathymetry-generated gravitational potential $V^{b}$ and attraction $g^{b}$. Geometrically, sea water masses are bounded by the reference sphere of radius $R$ and the ocean bottom described relatively to the reference sphere by the depth function $D^{b l}$. In this case a depth-dependent density model must be considered [12]

$\rho^{w}\left(D^{b l}\right)=\rho_{0}^{w}+\beta \sum_{i=1}^{2} a_{i} \rho^{w}\left(D^{b l}\right)$.

Respective coefficients are given as follows [59]

$$
\begin{aligned}
V_{n, m}^{b}= & \frac{3}{2 n+1} \frac{\Delta \rho_{0}^{w}}{\rho^{\text {earth }}} \sum_{k=0}^{\infty}\left(\begin{array}{c}
n+2 \\
k
\end{array}\right) \frac{(-1)^{k}}{R^{k+1}} \\
\times & {\left[\frac{F_{n, m}^{b l(k+1)}}{k+1}-\frac{a_{1} \beta}{\Delta \rho_{0}^{w}} \frac{F_{n, m}^{b l(k+2)}}{k+2}\right.} \\
& \left.-\frac{a_{2} \beta}{\Delta \rho_{0}^{w}} \frac{F_{n, m}^{b l(k+3)}}{k+3}\right] .
\end{aligned}
$$

Coefficients $F_{n, m}^{b l}$ are derived by applying a spherical analysis of the depth function $D^{b l}$ (and its powers) from the global bathymetric model (GBM) which describes geometry of the ocean bottom relief (lower bounding surface), see Eq. 11. There are no coefficients for the upper bounding surface since the spherical approxi- 
mation of the sea level is used. The nominal value of the ocean density contrast $\Delta \rho_{0}^{w}$ is defined as a difference between reference values of the crust density $\rho^{\text {crust }}$ and the mean surface seawater density $\rho_{0}^{w}$ in Eq. 16, i.e., $\Delta \rho_{0}^{\mathrm{W}}=\rho^{\text {crust }}-\rho_{0}^{\mathrm{w}}$. The value of the surface seawater density $\rho_{0}^{w}=1,027.91 \mathrm{~kg} / \mathrm{m}^{3}$ is used as the reference seawater density. For the adopted value of the reference crust density $\rho^{\text {crust }}$ of $2,670 \mathrm{~kg} / \mathrm{m}^{3}$, the reference ocean density contrast (at zero depth) equals $\Delta \rho_{0}^{w}=1,642.09 \mathrm{~kg} / \mathrm{m}^{3}$. The parameters of the depthdependent density term in Eq. 16 are given by the following values (Tenzer et al. [60]: $\beta=0.00637 \mathrm{~kg} / \mathrm{m}^{3}$, $a_{1}=0.7595 \mathrm{~m}^{-1}$ and $a_{2}=-4.3984 \times 10^{-6} \mathrm{~m}^{-2}$. These values were estimated from the oceanographic data of the World Ocean Atlas 2009 (provided by NOAA's National Oceanographic Data Center; [2, 10, 11, 19, 24]) and the World Ocean Circulation Experiment 2004 (provided by the German Federal Maritime and Hydrographic Agency; Gouretski and Koltermann [13]).

With reference to Tenzer et al. [58], we consider spectral expressions for computing the gravitational potential $V^{i}$ and attraction $g^{i}$ generated by the ice density contrast. In this study, we consider continental ice masses distributed over topography. Required coefficients $V_{\mathrm{n}, \mathrm{m}}^{i}$ read

$V_{\mathrm{n}, \mathrm{m}}^{i}=\frac{3}{2 n+1} \frac{\Delta \rho^{i c e}}{\rho^{\mathrm{earth}}}\left(F_{n, m}^{t u}-F_{\mathrm{n}, \mathrm{m}}^{i l}\right)$.

The ice density contrast $\Delta \rho^{\text {ice }}$ is defined as the difference between the reference density values of the crust $\rho^{\text {crust }}$ and glacial ice $\rho^{\text {ice }}$, i.e., $\Delta \rho_{0}^{i c e}=\rho^{\text {crust }}-\rho^{\text {ice }}$. For the adopted values of the reference crust density $2,670 \mathrm{~kg} / \mathrm{m}^{3}$ and the density of glacial ice $917 \mathrm{~kg} / \mathrm{m}^{3}$ (cf. [5]) the ice density contrast equals $1,753 \mathrm{~kg} / \mathrm{m}^{3}$. The density volume of the polar ice sheet is enclosed between the upper and lower ice bounds. The upper ice bound is identical with the upper topographic bound over areas of the polar ice sheet. Coefficients $F_{n, m}^{t u}=$ $F_{n, m}^{i u}$ in Eq. 18 associated with topography are defined in Eq. 15. Numerical coefficients $F_{n, m}^{i l}$ describing the lower ice bound read

$F_{n, m}^{i l}=\sum_{k=0}^{\infty}\left(\begin{array}{c}n+2 \\ k\end{array}\right) \frac{(-1)^{k}}{k+1} \frac{\Delta H_{n, m}^{(k+1)}}{R^{k+1}}$

where $\Delta H_{n, m}^{(k+1)}$ are global ice model (GIM) coefficients of degree $n$ and order $m$ generated from global elevation and ice-thickness data (cf. [58])

$$
\Delta H_{n, m}^{(k+1)}=\iint_{\Phi}\left[H^{t}\left(\Omega^{\prime}\right)-H^{i}\left(\Omega^{\prime}\right)\right]^{k+1} Y_{n, m}^{*}\left(\Omega^{\prime}\right) d \Omega^{\prime} .
$$

We further consider the gravitational potential $V^{s}$ and attraction $g^{s}$ generated by the sediment density contrast. Required coefficients $V_{n, m}^{s}$ are computed using the following expressions

$$
\begin{aligned}
V_{n, m}^{s}= & \frac{3}{2 n+1} \\
& \times \frac{1}{\rho^{\text {earth }}} \sum_{k=0}^{n+2}\left(\begin{array}{c}
n+2 \\
k
\end{array}\right) \frac{(-1)^{k}}{k+1} \frac{F_{n, m}^{s l}{ }^{(k+1)}-F_{n, m}{ }^{s u(k+1)}}{R^{k+1}},
\end{aligned}
$$

with $F_{n, m}^{s l}$ and $F_{n, m}^{s u}$ defined as

$$
\begin{aligned}
F_{n, m}^{s l(k+1)} & =\iint_{\Phi} \Delta \rho^{s}\left(\Omega^{\prime}\right)\left[H^{s l}\left(\Omega^{\prime}\right)\right]^{k+1} Y_{n, m}^{*}\left(\Omega^{\prime}\right) d \Omega^{\prime}, \\
F_{n, m}^{s u(k+1)} & =\iint_{\Phi} \Delta \rho^{s}\left(\Omega^{\prime}\right)\left[H^{s u}\left(\Omega^{\prime}\right)\right]^{k+1} Y_{n, m}^{*}\left(\Omega^{\prime}\right) d \Omega^{\prime} .
\end{aligned}
$$

The laterally varying sediment density contrast $\Delta \rho^{s}$ in Eq. 22 is defined as the difference between the reference density of the Earth's crust $\rho^{\text {crust }}$ and the laterally varying sediment density $\rho^{s}$, i.e.

$$
\begin{aligned}
\Delta \rho^{s}\left(\Omega^{\prime}\right)= & \rho^{\text {crust }} \\
-\rho^{s}\left(\Omega^{\prime}\right), & {\left[R-D^{s u}\left(\Omega^{\prime}\right) \geq r^{\prime} \geq R\right.} \\
& \left.-D^{s l}\left(\Omega^{\prime}\right): \Omega^{\prime} \in \Phi\right],
\end{aligned}
$$

where $D^{s u}$ and $D^{s l}$ are the depths (reckoned relative to the sphere of radius $\mathrm{R}$ ) of the upper and lower bounds of the sediment layer, respectively. The expressions for the laterally varying sediment density contrast layer utilise the functions $\mathrm{F}^{s l}$ and $\mathrm{F}^{s u}$ which combine the information on geometry of the volumetric sediment layer and its lateral density distribution. Their coefficients are evaluated by using a global sediment model (GSM) according to Eq. 22.

By analogy with Eqs. 21-23, we define the gravitational potential $V^{c}$ and attraction $g^{c}$ generated by the consolidated (crystalline) crust density. Coefficients $V_{n, m}^{c}$ are given by

$$
\begin{aligned}
V_{n, m}^{c}= & \frac{3}{2 n+1} \\
& \times \frac{1}{\rho^{\text {earth }}} \sum_{k=0}^{n+2}\left(\begin{array}{c}
n+2 \\
k
\end{array}\right) \frac{(-1)^{k}}{k+1} \frac{F_{n, m}^{c l(k+1)}-F_{n, m}^{c u(k+1)}}{R^{k+1}},
\end{aligned}
$$


where $F_{n, m}^{c l}$ and $F_{n, m}^{c u}$ are given by

$$
\begin{aligned}
\mathrm{F}_{\mathrm{n}, \mathrm{m}}^{c l(k+1)} & =\iint_{\Phi} \Delta \rho^{c}\left(\Omega^{\prime}\right)\left[H^{c l}\left(\Omega^{\prime}\right)\right]^{k+1} \mathrm{Y}_{\mathrm{n}, \mathrm{m}}^{*}\left(\Omega^{\prime}\right) \mathrm{d} \Omega^{\prime}, \\
\mathrm{F}_{\mathrm{n}, \mathrm{m}}^{c u(k+1)} & =\iint_{\Phi} \Delta \rho^{c}\left(\Omega^{\prime}\right)\left[H^{c u}\left(\Omega^{\prime}\right)\right]^{k+1} \mathrm{Y}_{\mathrm{n}, \mathrm{m}}^{*}\left(\Omega^{\prime}\right) \mathrm{d} \Omega^{\prime} .
\end{aligned}
$$

The laterally varying crust density contrast $\Delta \rho^{c}$ in Eq. 25 is defined as the difference between the reference density of the Earth's crust $\rho^{\text {crust }}$ and the laterally varying crust density $\rho^{c}$, i.e.

$$
\begin{aligned}
& \Delta \rho^{c}\left(\Omega^{\prime}\right)=\rho^{\text {crust }} \\
& -\rho^{c}\left(\Omega^{\prime}\right),\left[\mathrm{R}-D^{c u}\left(\Omega^{\prime}\right) \geq r^{\prime} \geq \mathrm{R}\right. \\
& \left.-D^{c l}\left(\Omega^{\prime}\right): \Omega^{\prime} \in \Phi\right],
\end{aligned}
$$

where $D^{c u}$ and $D^{c l}$ are the depths (reckoned relative to the sphere of radius $\mathrm{R}$ ) of the upper and lower bounds of the crust layer, respectively. The expressions for the laterally varying crust density contrast layer utilise the functions $\mathrm{F}^{c l}$ and $\mathrm{F}^{c u}$ which combine the geometry of the volumetric crust layer and its lateral density distribution. Their coefficients are computed from the global crust model (GCM) coefficients. Known vertical crustal density changes can be modelled using more volumetric crust layers, each having a specific lateral density distribution with varying depth and thickness. This is discussed in Section 3.

The expressions for computing the gravity field parameters, see Eqs. 1-3, and the gravitational field parameters generated by the topography, bathymetry, and ice, sediments, and consolidated crust components density contrasts, see Eqs. 15-26, are derived in terms of spherical harmonics utilising GGM, GEM, GBM, GIM, GSM, and GCM coefficients. Substituting these expressions to Eq. 4, we obtain the consolidated crust-stripped disturbing potential $T^{c}$ in the following form

$T^{c}(r, \Omega)=\frac{\mathrm{GM}}{R} \sum_{n=0}^{\bar{n}} \sum_{m=-n}^{n}\left(\frac{R}{r}\right)^{n+1} T_{n, m}^{c} Y_{n, m}(\Omega)$,

where

$T_{n, m}^{c}=T_{n, m}-V_{n, m}^{t}+V_{n, m}^{b}+V_{n, m}^{i}+V_{n, m}^{s}+V_{n, m}^{c}$,
Similarly, this substitution to Eqs. 5 and 6 yields

$$
\begin{aligned}
\delta g^{c}(r, \Omega) & =\frac{\mathrm{GM}}{R^{2}} \sum_{n=0}^{\bar{n}}\left(\frac{R}{r}\right)^{n+2}(n+1) \sum_{m=-n}^{n} T_{n, m}^{c} Y_{n, m}(\Omega), \\
\Delta g^{c}(r, \Omega) & =\frac{\mathrm{GM}}{R^{2}} \sum_{n=0}^{\bar{n}}\left(\frac{R}{r}\right)^{n+2}(n-1) \sum_{m=-n}^{n} T_{n, m}^{c} Y_{n, m}(\Omega) .
\end{aligned}
$$

Finally, the gravitational contribution generated by the homogeneous crust (inside the geoid) of the constant reference density $\rho^{\text {crust }}$ is subtracted from gravity field. This final step is again defined in the spectral representation. The upper bound of the homogeneous crust density layer is then given by the geoid surface while the lower bound is identical with the (model) Moho density interface. The gravitational potential $V^{\text {crust }}$ and attraction $g^{\text {crust }}$ generated by the homogeneous crust of the reference crust density $\rho^{\text {crust }}$ (inside the geoid) are

$V^{\text {crust }}(r, \Omega)=\frac{\mathrm{GM}}{R} \sum_{n=0}^{\bar{n}}\left(\frac{R}{r}\right)^{n+1} \sum_{m=-n}^{n} V_{n, m}^{\text {crust }} Y_{n, m}(\Omega)$,

and

$g^{\text {crust }}(r, \Omega)=\frac{\mathrm{GM}}{R^{2}} \sum_{n=0}^{\bar{n}}\left(\frac{R}{r}\right)^{n+2}(n+1) \sum_{m=-n}^{n} V_{n, m}^{\text {crust }} Y_{n, m}(\Omega)$.

The numerical coefficients $V_{n, m}^{\text {crust }}$ in Eqs. 30 and 31 are given by

$V_{n, m}^{\text {crust }}=\frac{3}{2 n+1} \frac{\rho^{\text {crust }}}{\rho^{\text {earth }}} \sum_{k=0}^{n+2}\left(\begin{array}{c}n+2 \\ k\end{array}\right) \frac{(-1)^{k}}{k+1} \frac{F_{n, m}^{M(k+1)}-F_{n, m}^{g(k+1)}}{R^{k+1}}$,

Coefficients $F_{n, m}^{g}$ are generated from the numerical coefficients $T_{n, m}$ of the disturbing gravity potential using the following formula (e.g. [59])

$F_{n, m}^{g}=\frac{T_{n, m}}{\gamma_{0}}$,

where $\gamma_{0}$ is normal gravity at the surface of the reference ellipsoidal GRS-80 [27]. Coefficients of the spherical Moho-depth function $F_{n, m}^{M}$ can be derived by the spherical analysis, see Eq. 11, of the depth of the Moho density interface with respect to the geoid that 
is derived from the global Moho model (GMM). In spherical approximation, the geocentric radius of the geoid is approximated by $R$. Hence, $F_{\mathrm{n}, \mathrm{m}}^{g} \cong 0$ and $V_{\mathrm{n}, \mathrm{m}}^{\text {crust }}$ become

$V_{n, m}^{\text {crust }} \cong \frac{3}{2 n+1} \frac{\rho^{\text {crust }}}{\rho^{\text {earth }}} F_{n, m}^{M}$.

The crust-corrected disturbing gravity potential $T^{M}$ is calculated by the expression

$$
\begin{aligned}
T^{M}(r, \Omega) & =T^{c}(r, \Omega)-V^{\text {crust }} \\
& =\frac{G M}{R} \sum_{n=0}^{\bar{n}}\left(\frac{R}{r}\right)^{n+1} \sum_{m=-n}^{n}\left(T_{n, m}^{c}-V_{n, m}^{\text {crust }}\right) Y_{n, m}(\Omega) .
\end{aligned}
$$

The crust-corrected gravity disturbance $\delta g^{M}$ is then given by

$$
\begin{aligned}
\delta g^{M}(r, \Omega)= & \delta g^{c}(r, \Omega)-g^{\text {crust }} \\
= & \frac{\mathrm{GM}}{R} \sum_{n=0}^{\bar{n}}\left(\frac{R}{r}\right)^{n+2}(n+1) \sum_{m=-n}^{n} \\
& \times\left(T_{n, m}^{c}-V_{n, m}^{\text {crust }}\right) Y_{n, m}(\Omega),
\end{aligned}
$$

and the crust-corrected gravity anomaly $\Delta g^{M}$ reads

$$
\begin{aligned}
\Delta g^{M}(r, \Omega)= & \delta g^{M}(r, \Omega)-\frac{2}{r} T^{M}(r, \Omega) \\
= & \frac{\mathrm{GM}}{R} \sum_{n=0}^{\bar{n}}\left(\frac{R}{r}\right)^{n+2}(n-1) \sum_{m=-n}^{n} \\
& \times\left(T_{n, m}^{c}-V_{n, m}^{\text {crust }}\right) Y_{n, m}(\Omega) .
\end{aligned}
$$

\section{Numerical examples}

The expressions defined in Section 2 were utilised to compute the consolidated crust-stripped gravity field. We computed and subsequently applied the topographic and crust-stripping corrections to gravity data (gravity disturbances and gravity anomalies). The applied gravimetric stripping corrections account for the gravitational contributions of density contrasts due to the ocean (bathymetry), ice, (soft and hard) sediments, and (upper, middle, and lower) crustal components. The computation of refined gravity data was done using the geopotential coefficients taken from EGM2008, the global topography/bathymetry model DTM2006.0, the global continental ice-thickness data ICE-5G and the global crustal model CRUST2.0. All computations were conducted globally on an equiangular 1 arc-deg geographical grid at the Earth's surface. The statistics of the topographic and crust-stripping corrections are summarized in Tables 1 and 2. Complete corrections to gravity anomalies comprise the combined contribution of the direct and secondary indirect effects [52, 53, 69]. Statistics of the stepwise consolidated crust-stripped gravity data are summarized in Tables 3 and 4 . The global corrections and the global gravity data were computed from the GGM, GEM, GBM and GIM coefficients with the spectral resolution complete to degree and order 180 of spherical harmonics. The GSM and GCM coefficients up to spherical harmonic degree and order 90 were used for a computation of the sediment and consolidate crust-stripping gravity corrections due to a 2 arc-deg spatial resolution of the CRUST2.0 global crustal model. CRUST2.0 [4], which is an upgrade of CRUST5.1 [26], contains information on the crustal thickness and the subsurface spatial distribution and density of the following global components: ice; ocean; soft and hard sediments; upper, middle, and lower (consolidated) crust. The use of the ICE-5G ice-thickness and DTM2006.0 bathymetry data instead of using the equiangular 2 arc-deg CRUST2.0 ice-thickness and bathymetry data improved significantly the accuracy of computed bathymetric and ice stripping gravity corrections. Further improvement in terms of the accuracy and resolution can be achieved once a more accurate global crustal (or lithospheric) model of a higher resolution becomes available.
Table 3 Statistics of the step-wise consolidated crust-stripped gravity disturbances

\begin{tabular}{lclcc}
\hline $\begin{array}{l}\text { Gravity } \\
\text { disturbances }\end{array}$ & Min [mGal] & Max [mGal] & Mean [mGal] & STD [mGal] \\
\hline EGM2008 & -303 & 293 & -1 & 29 \\
Topographic & -655 & 276 & -70 & 106 \\
Bathymetric & -516 & 727 & 261 & 230 \\
Ice & -516 & 732 & 283 & 200 \\
Sediment & -498 & 760 & 320 & 196 \\
Upper crust & -546 & 767 & 283 & 228 \\
Middle crust & -795 & 663 & 167 & 269 \\
Lower crust & $-1,315$ & 506 & 20 & 330 \\
\hline
\end{tabular}


Table 4 Statistics of the step-wise consolidated crust-stripped gravity anomalies

\begin{tabular}{llccc}
\hline $\begin{array}{l}\text { Gravity } \\
\text { anomalies }\end{array}$ & Min [mGal] & Max [mGal] & Mean [mGal] & STD [mGal] \\
\hline EGM2008 & -282 & 287 & -0.5 & 24 \\
Topographic & -382 & 341 & 41 & 73 \\
Bathymetric & -805 & -2 & -331 & 146 \\
Ice & -813 & -10 & -332 & 125 \\
Sediment & -867 & -46 & -365 & 126 \\
Upper crust & -825 & 5 & -336 & 147 \\
Middle crust & -802 & 154 & -228 & 171 \\
Lower crust & -851 & 391 & -43 & 209
\end{tabular}

The GGM coefficients taken from the EGM2008 [35] complete to the spherical harmonic degree 180 were used to compute the gravity field quantities according to Eqs. 2 and 3. The coefficients $E_{n, m}$ of the global topographic/bathymetric model DTM2006.0 and the coefficients $N_{n, m}$ of the global geoid model were used to generate the GEM coefficients $H_{n, m}^{t u}$

$H_{n, m}^{t u}=E_{n, m}-N_{n, m}$.

The DTM2006.0 coefficients $E_{n, m}$ describe the global geometry of the topographic heights above mean sea level (MSL) which are reckoned positive, and the bathymetric depths below MSL which are reckoned negative. The global topographic/bathymetric model DTM2006.0 was released together with EGM2008 by the U.S. National Geospatial-Intelligence Agency EGM development team. The geoid coefficients $N_{n, m}$ were generated from the numerical coefficients $T_{n, m}$ of the disturbing potential (derived from EGM2008) according to Eq. 33. The GEM coefficients complete to degree and order 180 were then used to compute the topographic corrections to gravity data. The coefficients $E_{n, m}$ and $N_{n, m}$ were further used to generate the GBM coefficients $D_{n, m}^{b l}$ according to the following expression

$D_{n, m}^{b l}=N_{n, m}-E_{n, m}$.

The GBM coefficients complete to degree and order 180 were used to compute the bathymetric stripping gravity corrections according to Eq. 17 formulated for a depth-dependent seawater density distribution model defined by the parameters $\Delta \rho_{0}^{w}, \beta, a_{1}$, and $a_{2}$ in Eq. 16. The equiangular 10 arc-min mean topographic heights computed by spatial averaging of the equiangular 30 arc-sec global elevation data from GTOPO30 (provided by the US Geological Survey's EROS Data Center) and the equiangular 10 arc-min continental icethickness data from ICE-5G made available by Peltier [36] were used to generate the GIM coefficients. The
GEM and GIM coefficients complete to a spherical harmonic degree and order 180 were then used to compute the ice density contrast stripping corrections to gravity data. The equiangular 2 arc-deg global data of the soft and hard sediment thickness and density from CRUST2.0 were used to compute globally the sediments density contrast stripping corrections to gravity data. This was done according to Eq. 21 formulated separately for the soft and hard sediments. The CRUST2.0 model consists of soft and hard sediment model components with the lateral density structure. The CRUST2.0 soft sediments vary in density from 1,700 to $2,300 \mathrm{~kg} / \mathrm{m}^{3}$ and reach a maximum thickness of about $2 \mathrm{~km}$, while the CRUST2.0 hard sediments vary between 2,300 and $2,600 \mathrm{~kg} / \mathrm{m}^{3}$ and become up to $18 \mathrm{~km}$ thick at places. The sediment density contrast was taken relative to the reference crustal density of $2,670 \mathrm{~kg} / \mathrm{m}^{3}$. The soft and hard sediment components and their density variability reflect to a certain degree the increasing density of sediments with depth due to compaction. In regional studies, a more accurate dependence of sediment density on depth may be adopted for sedimentary basins (cf. e.g., [3]). The equiangular 2 arc-deg global density and thickness data of the consolidated (upper, middle, and lower) crust components from CRUST2.0 were used to compute the crust density contrast stripping gravity corrections relative to the reference crustal density of $2,670 \mathrm{~kg} / \mathrm{m}^{3}$. The consolidated crust-stripped gravity data are shown in Fig. 1. The consolidated cruststripped gravity disturbances vary globally from $-1,315$ to $506 \mathrm{mGal}$. The range of the corresponding gravity anomalies is between -851 and $391 \mathrm{mGal}$. Tenzer et al. [61] used these refined gravity and (CRUST2.0) crust-thickness data to estimate the global average value of the crust-mantle density contrast and the corresponding global average density of the upper-most mantle. They have shown that the average values of the global upper-most mantle and of the crust-mantle density contrast are about $3,155 \mathrm{~kg} / \mathrm{m}^{3}$ and $485 \mathrm{~kg} / \mathrm{m}^{3}$, respectively. Tenzer et al. [56] demonstrated that the 

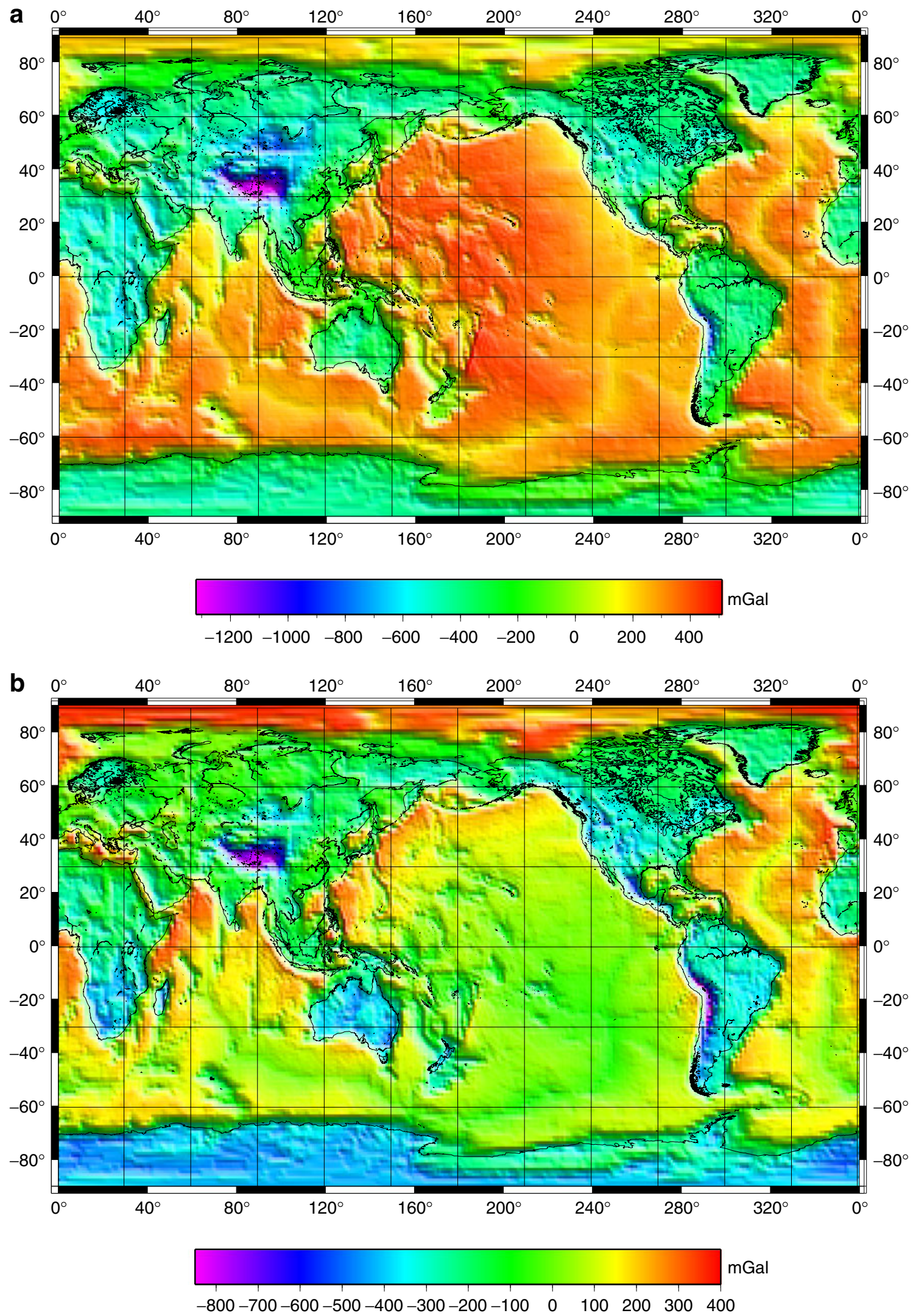

Fig. 1 The consolidated crust-stripped a gravity disturbances and $\mathbf{b}$ gravity anomalies computed globally on the equiangular 1 arc-deg grid at the Earth's surface 

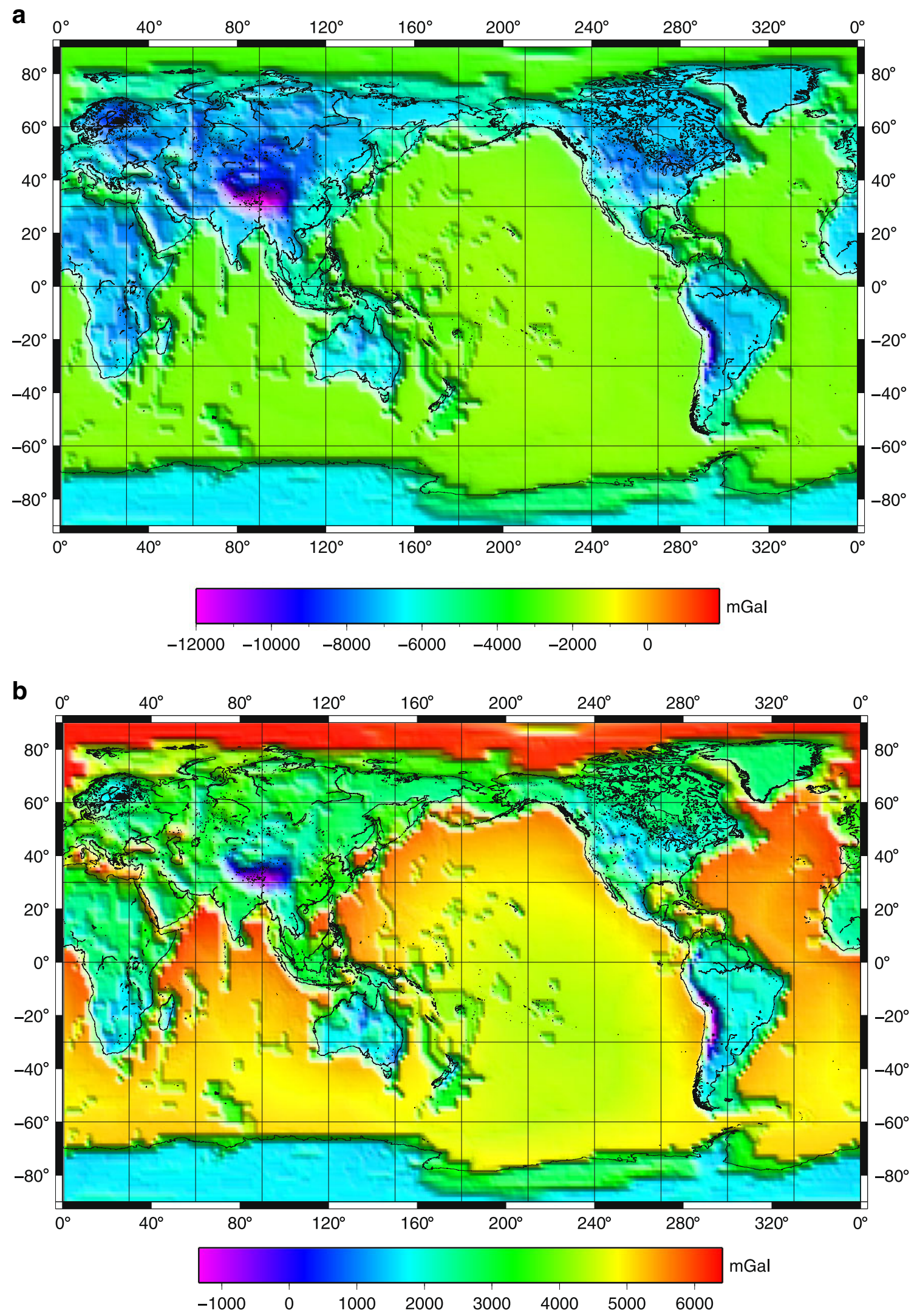

Fig. 2 The complete crust-corrected a gravity disturbances and $\mathbf{b}$ gravity anomalies computed globally on equiangular 1 arc-deg grid at the Earth's surface 
consolidated crust-stripped gravity data have the highest correlation with the Moho density interface among all refined gravity data obtained after applying the topographic and crust density contrast stripping corrections (summarized in Tables 3 and 4). The absolute correlation between the crust-thickness and refined gravity data reached 0.96 for the consolidated cruststripping gravity disturbances. Therefore, these refined gravity data should be the most suitable gravity data type for the recovery of the Moho density interface. However, such a gravimetric refinement of the Moho interface would translate also the signal of the topographic and crustal model uncertainties and the signal coming from the mantle lithosphere and deeper mantle into false information on the Moho density interface. The presence of the gravity signal due to the anomalous density structures within the Earth's mantle is typically suppressed by removing a long-wavelength part of the gravity signal. Nonetheless, the complete separation of these gravity sources is questionable due to the fact that there is hardly any unique distinction between the long-wavelength gravity signal from the mantle and the expected higher-frequency signal from the Moho geom- etry. The Moho refinement based purely on gravimetric methods without incorporating additional geophysical or geoscientific constraints is thus restricted due to the gravimetric signal superposition.

The equiangular 2 arc-deg global data of CRUST2.0 Moho depths we used to generate the GMM coefficients according to Eq. 24. The GMM coefficients were then used to compute the gravitational field generated by the homogeneous crust (beneath the geoid surface) of the reference density $\rho^{\text {crust }}=2,670 \mathrm{~kg} / \mathrm{m}^{3}$ with a spectral resolution complete to a spherical harmonic degree 90 . The subtraction of this gravitational field from the consolidated crust-stripped gravity data yields the final complete crust-corrected gravity field. The results are shown in Fig. 2. The crust-corrected gravity disturbances are everywhere negative and vary globally from $-12,010$ to $-1,902 \mathrm{mGal}$ with the mean of $-4,265 \mathrm{mGal}$, and the standard deviation is $1,089 \mathrm{mGal}$. The corresponding crust-corrected gravity anomalies are within $-1,339$ and $6,372 \mathrm{mGal}$ with the mean of $3,960 \mathrm{mGal}$, and the standard deviation is $1,391 \mathrm{mGal}$.

The global maps of the complete crust-corrected gravity field in Fig. 2 revealed the geometry of the

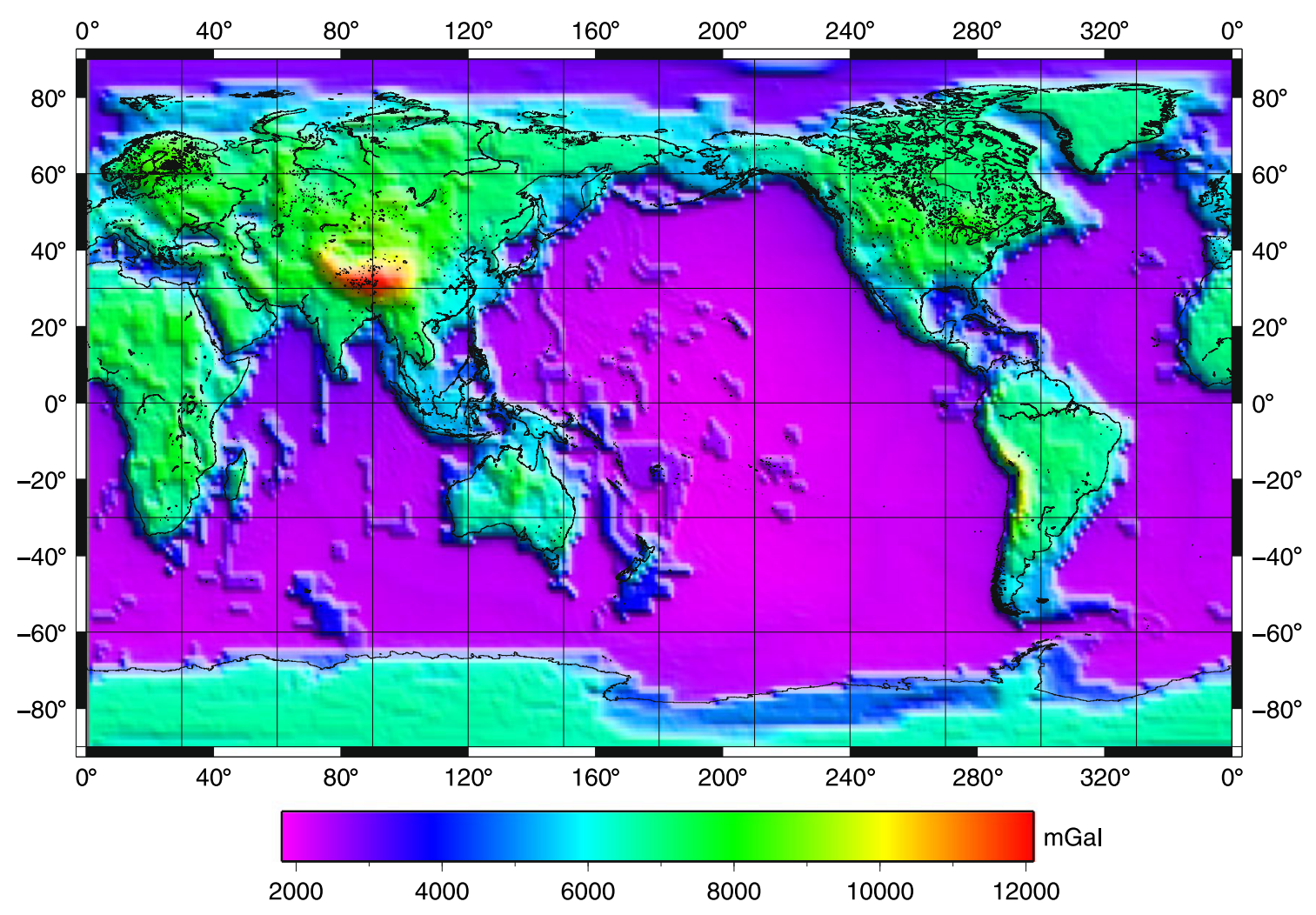

Fig. 3 The gravitational contribution of the whole Earth's crust computed globally on an equiangular 1 arc-deg grid at the Earth's surface 
Moho density interface and major features of the anomalous density structures within the Earth's mantle. Whereas the signature of the mantle density structure is more likely prevailing at long frequencies, the highfrequency gravity signal is dominated by the Moho geometry. However, the signal due to the deviations of the CRUST2.0 model from the real crust is also presented. We expect that the strongest long-wavelength part of the complete crust-corrected gravity signal is due to the thickness and density of the lithosphere, over which a weaker signal from the sub-lithospheric mantle is superposed. As seen in Fig. 2, the absolute maxima of the crust-corrected gravity disturbances are situated over continental regions and the corresponding minima over oceanic regions. The convergent ocean-tocontinent tectonic plate boundaries and the collision zones of continental tectonic plates represent the regions with the largest gravity signal spatial variations. The features of mid-ocean ridges and other tectonic plate boundaries clearly visible in Fig. 1 are much less pronounced in Fig. 2. This is due to the fact that the complete crust-corrected gravity data shown in Fig. 2 have a much large range of values than the corresponding consolidated crust-stripped gravity data shown in Fig. 1.

The gravitational contribution of the whole Earth's crust is shown in Fig. 3. It varies globally between 1,843 and $12,010 \mathrm{mGal}$ with the mean of $4,267 \mathrm{mGal}$, and the standard deviation is $2,089 \mathrm{mGal}$. This gravity field was obtained as the difference between the observed (EGM2008) and crust-corrected gravity data. Since the EGM2008 gravity data computed with a spectral resolution complete to the spherical harmonic degree 180 are mostly within a relatively small interval of $\pm 300 \mathrm{mGal}$ (cf. Table 3), the global as well as regional features of the gravitational field generated by the whole crust are very similar to the features of the complete crust-corrected gravity field. The maxima of these gravity differences thus correspond with the largest crustal thickness in mountainous regions with the presence of isostatic compensation. The corresponding minima are over the oceanic regions with a typically thin and heavier oceanic crust (compared to continental crust).

\section{Summary and concluding remarks}

We have formulated the spectral representation of gravity field generated by the Earth's crust density structures. This spectral representation utilise various types of spherical functions which describe individually the observed gravity field (GGM coefficients) and the gravitational field due to topography (GEM coefficients), bathymetry (GBM coefficients), ice density contrast (GIM and GEM coefficients), sediments density contrast (GSM coefficients), and crustal components density contrast (GCM coefficients). In addition, the gravitational field of the whole homogeneous crust was defined in terms of the GMM coefficients which describe the Moho geometry.

Methods for a spherical harmonic analysis and synthesis of gravity field based on the expressions given in Section 2 were applied in Section 3 to compute the complete crust-corrected gravity data and to estimate the gravitational contribution of the Earth's crust. The separation of the Earth's crust gravitational field from the sub-Moho gravity sources was done by subtracting the complete crust-corrected gravity field from the EGM2008 gravity data. The results revealed that the gravitational contribution generated by the Earth's crust (shown in Fig. 3) varies from 1,843 to 12,010 mGal. The complete crust-corrected gravity disturbances (shown in Fig. 2 a) are everywhere negative and vary within $-12,010$ and $-1,902 \mathrm{mGal}$. The similar range of these two gravity field quantities (as well as their similar spatial distribution) was explained by the fact that the EGM2008 gravity disturbances are distributed mainly within a relatively small interval of $\pm 300 \mathrm{mGal}$. The comparison of the crust-stripped and crust-corrected gravity data types (shown in Figs. 1 and 2) exhibited different patterns. Whereas the complete crustcorrected gravity data have a much more enhanced long-wavelength gravity signal of the lithosphere mantle, the high-frequency gravity signal of more shallow crustal structures and of the Moho geometry is more pronounced in the consolidated crust-stripped gravity data.

The description of the Earth's crust based on the stratigraphic layering with a variable height/depth, thickness, and lateral density distribution provides a more realistic and detailed representation of the Earth's crustal structure than, for instance, by the spherical homogenous layers used in the Preliminary Reference Earth Model (PREM; cf. [6]). We thus expect that a more realistic model of the Earth's inner structure can be compiled (and used in various geoscience applications) once lithospheric and deepmantle models become available.

Acknowledgements Pavel Novák was supported by the Project Plans MSM4977751301 of the Czech Ministry of Education, Youth and Sport. Peter Vajda was supported by the Slovak Research and Development Agency under the contract No. APVV-0194-10 and by Vega grant agency under project No. 2/0107/09. 


\section{References}

1. Arabelos, D., Mantzios, G., Tsoulis, D.: Moho depths in the Indian Ocean based on the inversion of satellite gravity data. In: Huen, W., Chen, Y.T. (eds.) Advances in Geosciences: Solid Earth, Ocean Science and Atmospheric Science, vol. 9, pp. 41-52. World Scientific (2007)

2. Antonov, J.I., Seidov, D., Boyer, T.P., Locarnini, R.A., Mishonov, A.V., Garcia, H.E.: World ocean atlas 2009, vol. 2: salinity. In: Levitus, S. (ed.) NOAA Atlas NESDIS 69, pp. 184. US Government Printing Office, Washington (2010)

3. Artemjev, M.E., Kaban, M.K., Kucherinenko, V.A., Demjanov, G.V., Taranov, V.A.: Subcrustal density inhomogeneities of the Northern Euroasia as derived from the gravity data and isostatic models of the lithosphere. Tectonophysics 240, 248-280 (1994)

4. Bassin, C., Laske, G., Masters, G.: The current limits of resolution for surface wave tomography in North America. EOS, Trans AGU 81, F897 (2000)

5. Cutnell, J.D., Kenneth, W.J.: Physics, 3rd edn. Wiley, New York (1995)

6. Dziewonski, A.M., Anderson, D.L.: Preliminary reference Earth model. Phys. Earth Planet. Inter. 25, 297-356 (1981)

7. Eshagh, M., Sjöberg, L.E.: Impact of topographic and atmospheric masses over Iran on validation and inversion of GOCE gradiometric data. J. Earth Space Phys. 34(3), 15-30 (2008)

8. Eshagh, M., Sjöberg, L.E.: Atmospheric effect on satellite gravity gradiometry data. J. Geodyn. 47, 9-19 (2009)

9. Eshagh, M., Bagherbandi, M., Sjöberg, L.E.: A combined global Moho model based on seismic and gravimetric data. Acta Geod. Geophys. Hung. 46(1), 25-38 (2011)

10. Garcia, H.E., Locarnini, R.A., Boyer, T.P., Antonov, J.I.: World ocean atlas 2009, vol. 3: dissolved Oxygen, apparent oxygen utilization, and oxygen saturation. In: Levitus, S. (ed.) NOAA Atlas NESDIS 70, pp. 344. US Government Printing Office, Washington (2010a)

11. Garcia, H.E., Locarnini, R.A., Boyer, T.P., Antonov, J.I.: World ocean atlas 2009, vol. 4: nutrients (phosphate, nitrate, silicate). In: Levitus, S. (ed.) NOAA Atlas NESDIS 71, pp. 398. US Government Printing Office, Washington (2010b)

12. Gladkikh, V., Tenzer, R.: A mathematical model of the global ocean saltwater density distribution. Pure Appl. Geophys. (2011) (submitted)

13. Gouretski, V.V., Koltermann, K.P.: Berichte des Bundesamtes für Seeschifffahrt und Hydrographie, vol. 35 (2004)

14. Grafarend, E., Engels, J.: The gravitational field of topographic isostatic masses and the hypothesis of mass condensation. Surv. Geophys. 14, 495-524 (1993)

15. Grafarend, E., Engels, J., Sorcik, P.: The gravitational field of topographic-isostatic masses and the hypothesis of mass condensation II - the topographic-isostatic geoid. Surv. Geophys. 17, 41-66 (1996)

16. Heck, B.: On Helmert's methods of condensation. J. Geod. 7, 155-170 (2003). doi:10.1007/s00190-003-0318-5

17. Heiskanen, W.H., Moritz, H.: Physical Geodesy. San Francisco, Freeman (1967)

18. Hinze, W.J.: Bouguer reduction density, why 2.67 ? Geophysics 68(5), 1559-1560 (2003). doi:10.1190/1.1620629

19. Johnson, D.R., Garcia, H.E., Boyer, T.P.: World ocean database 2009 tutorial. In: Levitus, S. (ed.) NODC Internal Report 21, pp. 18. NOAA Printing Office, Silver Spring (2009)

20. Kaban, M.K., Schwintzer, P., Tikhotsky, S.A.: Global isostatic gravity model of the Earth. Geophys. J. Int. 136, 519-536 (1999)
21. Kaban, M.K., Schwintzer, P.: Oceanic upper mantle structure from experimental scaling of vs. and density at different depths. Geophys. J. Int. 147, 199-214 (2001)

22. Kaban, M.K., Schwintzer, P., Artemieva, I.M., Mooney, W.D.: Density of the continental roots: compositional and thermal contributions. Earth Planet. Sci. Lett. 209, 53-69 (2003)

23. Kaban, M.K., Schwintzer, P., Reigber, Ch.: A new isostatic model of the lithosphere and gravity field. J. Geod. 78, 368385 (2004). doi:10.1007/s00190-004-0401-6

24. Locarnini, R.A., Mishonov, A.V., Antonov, J.I., Boyer, T.P., Garcia, H.E.: World ocean atlas 2009, vol. 1: temperature. In: Levitus, S. (ed.) NOAA Atlas NESDIS 68, pp. 184. US Government Printing Office, Washington (2010)

25. Makhloof, A.A.: The use of topographic-isostatic mass information in geodetic application. Dissertation D98, Institute of Geodesy and Geoinformation, Bonn (2007)

26. Mooney, W.D., Laske, G., Masters, T.G.: CRUST 5.1: a global crustal model at $5^{\circ} \times 5^{\circ}$. J. Geophys. Res. 103B, 727747 (1998)

27. Moritz, H.: Advanced Physical Geodesy. Wichmann, Karlsruhe (1980)

28. Nahavandchi, H.: A new strategy for the atmospheric gravity effect in gravimetric geoid determination. J. Geod. 77, 823828 (2004). doi:10.1007/s00190-003-0358-x

29. Novák, P.: Evaluation of gravity data for the Stokes-Helmert solution to the geodetic boundary-value problem. Technical Report, 207, University New Brunswick, Fredericton (2000)

30. Novák, P., Vaníèek, P., Martinec, Z., Veronneau, M.: Effects of the spherical terrain on gravity and the geoid. J. Geod. 75(9-10), 491-504 (2001). doi:10.1007/s001900100201

31. Novák, P., Grafarend, E.W.: The ellipsoidal representation of the topographical potential and its vertical gradient. J. Geod. 78(11-12), 691-706 (2005). doi:10.1007/s00190-005-0435-4

32. Novák, P., Grafarend, E.W.: The effect of topographical and atmospheric masses on spaceborne gravimetric and gradiometric data. Stud. Geophys. Geod. 50(4), 549-582 (2006). doi:10.1007/s11200-006-0035-7

33. Novák, P.: High resolution constituents of the Earth gravitational field. Surv. Geophys. 31(1), 1-21 (2010a)

34. Novák, P.: Direct modeling of the gravitational field using harmonic series. Acta Geodynamica at Geomaterialia 157(1), 35-47 (2010b)

35. Pavlis, N.K., Holmes, S.A., Kenyon, S.C., Factor, J.K.: An Earth gravitational model to degree 2160: EGM 2008. Presented at session G3: "GRACE science applications", EGU Vienna (2008)

36. Peltier, W.R.: Global glacial isostasy and the surface of the ice-age Earth: the ICE-5G (VM2) model and GRACE. Ann. Rev. Earth and Planet. Sci. 32, 111-149 (2004)

37. Ramillien, G.: Gravity/magnetic potential of uneven shell topography. J. Geod. 76, 139-149 (2002). doi:10.1007/s00190002-0193-5

38. Rummel, R., Rapp, R.H., Sünkel, H., Tscherning, C.C.: Comparison of Global Topographic/Isostatic Models to the Earth's Observed Gravitational Field, Report, 388. The Ohio State University, Columbus, Ohio, 43210-1247 (1988)

39. Sjöberg, L.E.: Terrain effects in the atmospheric gravity and geoid correction. Bull. Geod. 64, 178-184 (1993)

40. Sjöberg, L.E.: The atmospheric geoid and gravity corrections. Boll. Geod. Sci. Affini 57(4), 421-435 (1998)

41. Sjöberg, L.E.: The IAG approach to the atmospheric geoid correction in Stokes's formula and a new strategy. J. Geod. 73, 362-366 (1999). doi:10.1007/s00190005025 
42. Sjöberg, L.E., Nahavandchi, H.: On the indirect effect in the Stokes-Helmert method of geoid determination. J. Geod. 73, 87-93 (1999). doi:10.1007/s001900050222

43. Sjöberg, L.E.: Topographic effects by the Stokes-Helmert method of geoid and quasi-geoid determinations. J. Geod. 74(2), 255-268 (2000). doi:10.1007/s001900050284

44. Sjöberg, L.E., Nahavandchi, H.: The atmospheric geoid effects in Stokes formula. Geophys. J. Int. 140, 95-100 (2000). doi:10.1046/j.1365-246x.2000.00995.x

45. Sjöberg, L.E.: Topographic and atmospheric corrections of gravimetric geoid determination with special emphasis on the effects of harmonics of degrees zero and one. J. Geod. 75, 283-290 (2001). doi:10.1007/s001900100174

46. Sjöberg, L.E.: The effects of Stokes's formula for an ellipsoidal layering of the Earth's atmosphere. J. Geod. 79, 675681 (2006), doi:10.1007/s00190-005-0018-4

47. Sjöberg, L.E.: Topographic bias by analytical continuation in physical geodesy. J. Geod. 81, 345-350 (2007). doi:10.1007/s00190-006-0112-2

48. Sjöberg, L.E.: Solving Vening Meinesz-Moritz inverse problem in isostasy. Geophys. J. Int. 179, 1527-1536 (2009)

49. Sun, W., Sjöberg, L.E.: Convergence and optimal truncation of binomial expansions used in isostatic compensations and terrain corrections. J. Geod. 74, 627-636 (2001)

50. Sünkel, H.: Global topographic-isostatic models. In: Sünkel, H. (ed.) Mathematical and Numerical Techniques in Physical Geodesy. Lecture Notes in Earth Sciences, vol. 7, pp. 417462. Springer-Verlag (1986)

51. Tenzer, R.: Spectral domain of Newton's integral. Boll. Geod. Sci. Affini 2, 61-73 (2005)

52. Tenzer, R., Hamayun, K., Vajda, P.: Global secondary indirect effects of topography, bathymetry, ice and sediments. Contrib. Geophys. Geod. 38(2), 209-216 (2008a)

53. Tenzer, R., Hamayun, K., Vajda, P.: Global map of the gravity anomaly corrected for complete effects of the topography, and of density contrasts of global ocean, ice, and sediments. Contrib. Geophys. Geod. 38(4), 357-370 (2008b)

54. Tenzer, R., Hamayun, K., Vajda, P.: Global maps of the CRUST 2.0 crustal components stripped gravity disturbances. J. Geophys. Res. 114(B), 05408 (2009a)

55. Tenzer, R., Vajda, P., Hamayun, K.: Global atmospheric corrections to the gravity field quantities. Contrib. Geophys. Geodes. 39(3), 221-236 (2009b)

56. Tenzer, R., Hamayun, K., Vajda, P.: A global correlation of the step-wise consolidated crust-stripped gravity field quantities with the topography, bathymetry, and the CRUST 2.0 Moho boundary. Contrib. Geophys. Geod. 39(2), 133-147 (2009c)

57. Tenzer, R., Vajda, P., Hamayun, K.: A mathematical model of the bathymetry-generated external gravitational field. Contrib. Geophys. Geod. 40(1), 31-44 (2010a)

58. Tenzer, R., Abdalla, A., Vajda, P., Hamayun, K.: The spherical harmonic representation of the gravitational field quant ities generated by the ice density contrast. Contrib. Geophys. Geod. 40(3), 207-223 (2010b)

59. Tenzer, R., Novák, P., Gladkikh, V.: The bathymetric stripping corrections to gravity field quantities for a depthdependent model of the seawater density. Mar. Geod. (2011a) Submitted 29 Oct 2010

60. Tenzer, R., Novák, P., Gladkikh, V.: On the accuracy of the bathymetry-generated gravitational field quantities for a depth-dependent seawater density distribution. Stud. Geophys. Geod. (2011b) (accepted)

61. Tenzer, R., Hamayun, K., Novák, P., Gladkikh, V., Vajda, P.: Global crust-mantle density contrast estimated from EGM2008, DTM2008, CRUST2.0, and ICE-5G. Pure Appl. Geophys. (2011c) (submitted)

62. Torge, W.: Geodesy, 3rd edn. Walter de Gruyter, Berlin (2001)

63. Tsoulis, D.: Spherical harmonic computations with topographic/isostatic coefficients. Reports in the series IAPG/FESG, rep. no. 3 (ISBN 3-934205-02-X). Institute of Astronomical and Physical Geodesy, Technical University of Munich (1999)

64. Tsoulis, D.: A Comparison between the Airy-Heiskanen and the Pratt-Hayford isostatic models for the computation of potential harmonic coefficients. J. Geod. 74(9), 637-643 (2001). doi:10.1007/s001900000124

65. Tsoulis, D.: Spherical harmonic analysis of the CRUST2.0 global crustal model. J. Geod. 78(1/2), 7-11 (2004a)

66. Tsoulis, D.: Two Earth gravity models from the analysis of global crustal data. Z. Vermess. Wes. 129(5), 311-316 (2004b)

67. Tsoulis, D., Venesis, C.: Numerical analysis of crustal database CRUST2.0 and comparisons with Airy defined Moho signatures. Geod. Kartogr. 55(4), 175-191 (2006)

68. Tsoulis, D., Grigoriadis, V.N., Tziavos, I.N.: Evaluation of the CRUST2.0 global database for the Hellenic area in view of regional applications of gravity field modeling. In: Kilicoglu, A., Forsberg, R. (eds.) Gravity Field of the Earth. Proceedings of the 1st International Symposium of the International Gravity Field Service, General Command of Mapping, Special Issue, vol. 18, pp. 348-353. Ankara (2007)

69. Vajda, P., Vaníček, P., Novák, P., Tenzer, R., Ellmann, A.: Secondary indirect effects in gravity anomaly data inversion or interpretation. J. Geophys. Res., Solid Earth 112, B06411 (2007). doi:10.1029/2006JB004470

70. Vaníček, P., Najafi, M., Martinec, Z., Harrie, L., Sjöberg, L.E.: Higher-degree reference field in the generalised Stokes-Helmert scheme for geoid computation. J. Geod. 70(3), 176-182 (1995). doi:10.1007/BF0094369

71. Wild, F., Heck, B.: Effects of topographic and isostatic masses in satellite gravity gradiometry. In: Proceedings: Second International GOCE User Workshop GOCE. The Geoid and Oceanography, ESA-ESRIN, Frascati, Italy, March 8-10, 2004 (ESA SP-569, June 2004), CD-ROM (2004) 